\title{
Uma história das travestis em Fortaleza
}

A Story of The Transvestites in Fortaleza

Paulo Roberto Souto Maior Júnior

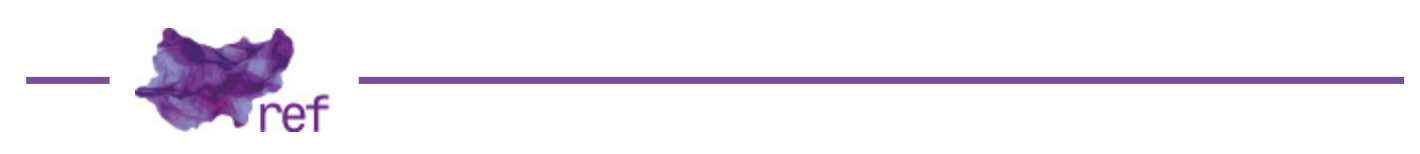

VERAS, Elias.

Travestis: carne, tinta e papel.

Curitiba: Prismas, 2017.

O historiador Elias Ferreira Veras, professor da Universidade Federal de Alagoas e pesquisador do Laboratório de Estudos de Gênero e História (LEGH) da Universidade Federal de Santa Catarina (UFSC), trouxe ao público o importante livro Travestis: carne, tinta e papel, resultado de sua tese de doutorado defendida em 2015 na UFSC. O que parece mais surpreendente, contudo, é que o trabalho tem a historiografia como lugar de fala. Surpreendente porque ousaria dizer que a historiografia brasileira ainda tem uma lacuna de produções sobre temas LGBTTTQIA.

De que trata o livro? Narra a história da emergência do sujeito travesti em Fortaleza, notadamente a partir da mídia. A história conta com um recorte temporal que observa diferenças e rupturas e o livro oscila entre dois tempos, o tempo das perucas e o tempo dos hormônios farmacopornográficos, cuja transformação se deu na transição das décadas de 1970-80. O tempo das perucas especifica um momento de experiências privadas, caracterizadas por festas discretas e/ou bailes carnavalescos. Por sua vez, o tempo dos hormônios diagnostica que a partir de determinado momento o termo travesti, conceito que, temporalmente, carrega diversas camadas de sentido (Reinhart KOSELLECK, 2013), estende-se a um sujeito sexual ambíguo, efeito de modificação tecnológica e resultando em modificações no corpo; nessa rede discursiva, mesclando ao mesmo tempo fascínio e controle, a experiência travesti se modificava, suscitando subjetividades inéditas na constituição dos sujeitos.

A obra do historiador se soma a outras vozes que fabricaram passados a respeito de pessoas que se relacionavam ou desejavam pessoas do mesmo sexo. Poderia aqui citar historiadores e historiadoras do naipe de Luiz Mott, Ligia Bellini, Durval Muniz de Albuquerque e James Green. Veras aproxima-se deles/as pela causa que advoga, mas ao mesmo tempo se distancia pelas inspirações teóricas do seu trabalho, talvez uma história cultural atravessada pela teoria queer norte-americana e europeia. Assim, ele risca e arrisca no seu campo. Risca porque grafita na história temas que por muito ficaram ausentes na área e arrisca no sentido de usar teorias do seu tempo, do tempo que lhe atravessa, para ler um passado não muito distante. E o faz com maestria.

Fiel a uma bibliografia atualizada acerca dos estudos de gênero, aciona Judith Butler, Michel Foucault e Paul Beatriz Preciado. Da filósofa norte-americana vê no conceito de performatividade uma possibilidade de leitura das experiências travestis; do autor de História da sexualidade: a vontade de saber - inclusive obra parafraseada no livro - recorre às noções de subjetividade, bem como à análise discursiva que guia todo o trabalho; e, finalmente, do filósofo 
espanhol Paul Beatriz Preciado se apoia em um dos movimentos mais originais do texto, o conceito de farmacopornografia.

Não deixa de fora as regras estabelecidas para uma operação historiográfica (Michel de CERTEAU, 2010). Suas análises reconhecem, numa atitude de ética intelectual, o débito com aqueles que o antecederam e, de certo modo, abriram caminhos para pensar sua questão. Ler Travestis: carne, tinta e papel é se deparar com nomes importantes na bibliografia travesti brasileira, são eles: Hélio Silva; Neuza Maria de Oliveira; Regina Maria Erdmann; Don Kulich, Larissa Pelúcio, dentre outros.

A importância política do seu trabalho, no que se refere à cisão que ajuda a fazer na nossa historiografia, está conectada a debates já empreendidos pelo autor. Em 2014 publicou com a historiadora Joana Maria Pedro o provocativo "Os silêncios de Clio: escrita da história e (in)visibilidade das homossexualidades no Brasil" que examina a ausência de pesquisas sobre o tema nos departamentos de história no país. No artigo, sugerem que a teoria queer pode ser uma oportuna categoria de análise histórica. Nas suas palavras: "Uma escrita da história que leve em consideração tal perspectiva acena para uma mudança epistemológica que efetivamente rompa com a lógica binária e com seus efeitos de classificação e exclusão" (Elias Ferreira VERAS; Joana Maria PEDRO, 2014, p. 104). Elias Veras cumpriu no livro o que havia sugerido no artigo publicado com sua então orientadora um ano antes.

Ao acionar fontes literárias, visuais, orais e impressas, Veras comanda uma narrativa que mostra suas personagens distantes das categorias binárias que até os anos 1970 marcavam as produções em Ciências Humanas no Ocidente. Ao lançar mão de entrevistas com cearenses que viveram a experiência de se travestir, o historiador tem o cuidado de colocar os relatos em embate, combate e debate com outras fontes, a exemplo dos confetes, maquiagens, fantasias e lantejoulas presentes nas matérias carnavalescas da revista Manchete.

Para aguçar o desejo de leitura, apresento brevemente os três capítulos. O primeiro, como já esboçado neste texto, trata da emergência das travestis em Fortaleza, rompendo temporalidades e com isso modificando subjetividades; o que não se dá sem enfrentamentos e combates bem narrados pelo historiador.

O segundo capítulo, por sua vez, mostra que quando a capa da revista Playboy com Roberta Close apareceu nas bancas em maio de 1984, os sujeitos trans vieram ao espaço público, fora dos momentos das festas carnavalescas. Era inimaginável até então que uma transexual aparecesse pelada numa revista masculina. Por resultado, o que se viu foi uma "confusão de gênero" (VERAS, 2017 , p. 120). Por outro lado, nesse momento do livro, no trato com as imagens, a crítica documental das imagens poderia ter se dado com um pouco mais de afinco, percebendo para além das suas condições de possibilidade, os efeitos que eventualmente elas podem ter suscitado.

Porém, como diz o adágio popular, nem tudo eram flores, ou melhor, lantejoulas, perucas, purpurinas e maquiagem. Havia a violência e o estigma, duas das principais maneiras de ferir o outro, podendo tirar dos sujeitos pedaços de vida. Eis o que trata o último capítulo "O dispositivo de estigma e os contra-discursos travestis." Embora a imprensa tentasse estabelecer controle sobre as travestis distribuindo os seus nomes das páginas policiais, elas não deixavam de lutar e mostrar "a dor e a delícia de ser o que 'é'" (Caetano VELOSO, 1986) - bem capturadas pela lente precisa de Elias Veras.

\section{Referências}

CERTEAU, Michel de. "A operação historiográfica". In: CERTEAU, Michel de. A Escrita da História. Trad. de Maria de Lourdes Menezes. Rio de Janeiro: Forense-Universitária, 2010, p. 65-130.

KOSELLECK, Reinhart. Futuro Passado: Contribuição à semântica do tempo histórico. Rio de Janeiro: Contraponto-Ed. PUC-Rio, 2013.

VELOSO, Caetano. “Dom de lludir”. In: VELOSO, Caetano. Totalmente Demais. Polygram, 1986.

VERAS, Elias; PEDRO, Joana Maria. "Os silêncios de Clio: escrita da história e (in)visibilidade das homossexualidades no Brasil". Tempo e Argumento, v. 6, n. 13, p. 90-109, 2014. Disponível em: http://www.revistas.udesc.br/index.php/tempo/article/view/21 75180306132014090/4161. Acesso em $30 / 05 / 2018$.

VERAS, Elias. Travestis: carne, tinta e papel. Curitiba: Prismas, 2017.

Paulo Roberto Souto Maior Júnior

Doutorando pelo Programa de Pós-Graduação em História da UFSC

Licenciado em História pela Universidade Federal de Campina Grande (2013) e mestre em História pela Universidade Federal de Pernambuco (2015). Pesquisador do Laboratório de Estudos de 
Gênero e História (LEGH) da UFSC. É coordenador da coleção História das Sexualidades brasileiras da editora Prismas. Bolsista de doutorado do CNPq.

Universidade Federal de Santa Catarina, Programa de Pós-Graduação em História

R. Eng. Agronômico Andrei Cristian Ferreira, s/n - Trindade

88040-900 - Florianópolis - SC - Brasil

+55 (48) 3721-4136-ppghst@contato.ufsc.br

paulosoutom@gmail.com

\section{COMO CITAR ESSE ARTIGO DE ACORDO COM AS NORMAS DA REVISTA}

MAIOR JUNIOR, Paulo Souto. "Uma história das travestis em Fortaleza". Revista Estudos Feministas, Florianópolis, v. 27, n. 1, e56051, 2019.

CONTRIBUIÇÃO DE AUTORIA

Não se aplica

FINANCIAMENTO

CNPq

CONSENTIMENTO DE USO DE IMAGEM

Não se aplica

APROVAÇÃO DE COMITÊ DE ÉTICA EM PESQUISA

Não se aplica

\section{CONFLITO DE INTERESSES}

Não se aplica

\section{LICENÇA DE USO}

Este artigo está licenciado sob a Licença Creative Commons CC-BY. Com essa licença você pode compartilhar, adaptar, criar para qualquer fim, desde que atribua a autoria da obra.

\section{HISTÓRICO}

Recebido em 26/03/2018

Aprovado em 07/07/2018

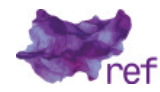

